\title{
Rimbaud poéticien, éd. Olivier Bivort
}

\section{Ida Merello}

\section{(2) OpenEdition}

\section{Journals}

\section{Edizione digitale}

URL: http://journals.openedition.org/studifrancesi/5403

DOI: 10.4000/studifrancesi.5403

ISSN: 2427-5856

\section{Editore}

Rosenberg \& Sellier

\section{Edizione cartacea}

Data di pubblicazione: 1 dicembre 2016

Paginazione: 554-555

ISSN: 0039-2944

\section{Notizia bibliografica digitale}

Ida Merello, «Rimbaud poéticien, éd. Olivier Bivort », Studi Francesi [Online], 180 (LX | III) | 2016, online dal 01 janvier 2017, consultato il 18 septembre 2020. URL : http://journals.openedition.org/ studifrancesi/5403 ; DOI : https://doi.org/10.4000/studifrancesi.5403

\section{Questo documento è stato generato automaticamente il 18 settembre 2020.}

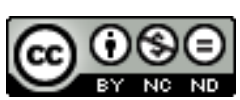

Studi Francesi è distribuita con Licenza Creative Commons Attribuzione - Non commerciale - Non opere derivate 4.0 Internazionale. 


\title{
Rimbaud poéticien, éd. Olivier Bivort
}

\author{
Ida Merello
}

\section{NOTIZIA}

Rimbaud poéticien, sous la direction d'Olivier BIVORT, Paris, Classiques Garnier 2015, 252

pp.

1 Una raccolta di studi sotto questo titolo è già una presa di posizione, dal momento che implica un'ars poetica di Rimbaud, per molto tempo trascurata, se non addirittura rifiutata, in base alla concezione di una modernità sprezzante e rivoluzionaria del poeta, che avrebbe rifiutato qualsiasi idea del fare antecedente al fare poetico stesso. Qui di seguito diamo conto di tutti i contributi, uniti da questa preventiva condivisione.

Olivier BIVORT, Rimbaud poéticien: une introduction, pp.7-14. Nell'introduzione Bivort mostra la necessità di una rilettura di quelle Lettres du Voyant anche troppo citate, per ricollocarle nell'ambito di un'ars poetica.

Dominique COMBE (Rimbaud poéticien?, pp. 15-28) posiziona la poetica di R. proprio nel solco dei manifesti della tradizione classica, mostrandone la volontà di sistema che la critica novecentesca, in base a un'immagine antiteorica di R., non ha preso in considerazione fino agli interventi di André Guyaux e Jacques Roubaud.

4 Henri scePI (Rimbaud, poésie objective, pp. 29-46) esercita la sua indagine sul termine «objectif» utilizzato nella lettera a Izambard, e vi legge la volontà di andare oltre il lirismo romantico in nome di una poesia che accompagni l'azione, con una connotazione egoistica del primo e politico-sociale della seconda.

5 Per Hermann H. WETZel (La poétique de Rimbaud est-elle à la hauteur de ses poèmes?, pp. 47-58) è invece evidente che la poetica di R. non è all'altezza della poesia, e ne trova dimostrazione nell'uso di testi poetici anche all'interno delle lettere del Veggente come migliore spiegazione di quanto viene affermato. 
Yann MORTELETTE (Rimbaud et la poétique parnassienne, pp.59-72) ripercorre la carriera poetica di R., che dapprima individua la modernità nei poeti del Parnasse, riconosce tra i maestri Banville, ma poi passa alla parodia satirica e al sarcasmo.

7 Yves ReBoul (Mérat le Voyant, pp. 73-90) si interroga sulla presenza di Mérat tra $\mathrm{i}$ veggenti nella lettera a Demeny. Mérat è infatti un parnassiano formalista, eppure R. ha apprezzato in lui la verità delle rappresentazioni erotiche e l'aspirazione, presente nelle Chimères, a un avvenire materialista.

8 Yoshikazu NAKAJI (Rimbaud autocritique, pp. 91-104) prende in considerazione Alchimie du verbe, secondo testo del dittico Délires di Une saison en enfer, e procede a un'analisi serrata della critica in proposito di Michel Murat e di Stephe Murphy, mettendo a confronto le due visioni per discendere a fondo nel rapporto tra lucidità e follia e mostrare come sia sottile l'equilibrio tra rappresentazione finzionale e autentica espressione di un'esperienza.

Michel mURAT (La "puissance d'ironie" de Rimbaud, pp. 105-118) parte dall'affermazione di Verlaine circa l'ironia rimbaldiana per mostrare, proprio attraverso lo spettro delle valenze dell'ironia, sempre più complesse e difficili da decifrare, la lontananza dall'ironia romantica e l'emergere di un sarcasmo distruttivo.

Mario RICHTER (Autour de la poétique de la Beauté dans "Une saison en enfer", pp.119-124) prende in considerazione il riferimento alla Beauté all'inizio della Saison en enfer per stabilire analogie col «monstre énorme» de L'Hymne à la beauté di Baudelaire.

11 Seth WHIDDEN (Le Sacré dans "Alchimie du verbe", pp. 125-139) collega la scrittura della Saison al momento politico, ossia la caduta del Secondo Impero e la Comune, stabilendo una relazione con un testo che si presenta come rivoluzionario rispetto alle strutture preesistenti.

12 Aurélia CERVONI (Rimbaud sophiste, pp.141-150) attribuisce a una forma di captatio benevolentiae l'uso del termine sophisme che R. utilizza in Alchimie du Verbe per descrivere Voyelles e le poesie del 1872. In tal modo, nel momento stesso in cui impiega un termine della retorica più consumata per definire il suo lavoro, chiede in realtà che si vada oltre e si cerchi una verità che non appartiene alla retorica.

13 Jean-Luc STEINMTEZ (Rimbaud et l'hallucination, pp. 151-160) inserisce l'hallucination simple e l'hallucination des mots di cui R. parla in Alchimie du verbe, rintracciando una rete associativa di termini, come dérèglement des sens, effarement, voyant, che rendono conto di un tentativo di oltrepassare i limiti del rapporto con la realtà e di fondare su questa esperienza una poetica, realizzata soprattutto nelle Illuminations.

14 André GUYAUX (Rimbaud et les avatars du moi, pp. 161-168) osserva come sia frequente in R. l'uso di un'altra identità, non solo per je est un autre, ma nel Bateau ivre, o in Bottom. Qui viene messa sotto esame la meno appariscente, in Enfance II, dove il pronome le, sottolineato, sembra sostituire "me".

15 Andrea schellino (Bruit et harmonie dans les Illuminations, pp.169-178) riprende la questione talvolta evocata dell'incoerenza e della disarmonia delle Illuminations, indagando il rapporto tra armonia e disarmonia tenendo presente l'ascendenza romantica e vedendo il silenzio come naturale ricomposizione della dialettica. Maria Emanuela RAFFI (Départ. Des rumeurs et des bruits, pp.179-188) nel solco della ricerca di una poetica rimbaldiana, si sofferma su Départ, visto come un'arte poetica condensata, in cui $R$. voltando le spalle alle visioni intende staccarsi dalla poesia 
soggettiva. Ma che cosa intravede avanti? Il testo mostra il delinearsi di due aree semantiche, l'una legata ai sentimenti e alle emozioni, l'altra alle sensazioni: l'A. si domanda se l'avvenire auspicato per la poesia non sia per R. quello del mettersi in ascolto dell'esistenza con tutti i mezzi a disposizione con un obiettivo di conoscenza.

17 Adrien cavallaro (Pour une poétique de la formule rimbaldienne au $\mathrm{xx}^{\mathrm{e}}$ siècle, pp. 189-232) compie un originale ed euristico percorso attraverso il modo in cui la poetica delle lettere del Veggente e delle Illuminations sono state interpretate nel xx secolo. 